Article

\title{
Quantitative Immobilization of Phthalocyanine onto Bacterial Cellulose for Construction of a High-Performance Catalytic Membrane Reactor
}

\author{
Shiliang Chen * and Qiaoling Teng \\ Qianjiang College, Hangzhou Normal University, Hangzhou 310012, China; tengq11996@sina.com \\ * Correspondence: bruceblue@zju.edu.cn; Tel.: +86-571-28861372
}

Received: 4 July 2017; Accepted: 22 July 2017; Published: 24 July 2017

\begin{abstract}
We report the fabrication of a tetra-amino cobalt (II) phthalocyanine (CoPc)-immobilized bacterial cellulose $(\mathrm{BC})$ functional nanocomposite, $\mathrm{CoPc} @ \mathrm{BC}$, by quantitative immobilization of $\mathrm{CoPC}$ onto a $\mathrm{BC}$ membrane. Lab-cultured $\mathrm{BC}$ was oxidized by $\mathrm{NaIO}_{4}$ to generate aldehyde groups on $\mathrm{BC}$ for the subsequent $\mathrm{CoPc}$ immobilization, the processing conditions were optimized by monitoring both the generated aldehyde content and the resulting CoPc loading. X-ray photoelectron spectroscopy (XPS) was employed to characterize the change of the element bonding environment during the functionalization processes. The $\mathrm{CoPc} @ \mathrm{BC}$ functional nanocomposite was utilized for the treatment of reactive red X-3B dye wastewater. The CoPc molecules in the CoPc@BC nanocomposite can function as an "antenna" to adsorb the target anionic dye molecules, the adsorption takes place both on the surface and in the interior of CoPc@BC. A catalytic membrane reactor (CMR) was assembled with the CoPc@BC nanocomposite, the performance of $\mathrm{CMR}$ was evaluated based on the catalytic oxidation behavior of reactive red X-3B, with $\mathrm{H}_{2} \mathrm{O}_{2}$ as an oxidant. Highly-reactive hydroxyl radical $(\mathrm{OH})$ was involved in the catalytic oxidation process, as detected by electron paramagnetic resonance (EPR). Under optimal operating conditions of a flow rate of $6 \mathrm{~mL} / \mathrm{min}$, a reaction temperature of $50{ }^{\circ} \mathrm{C}$, and an $\mathrm{H}_{2} \mathrm{O}_{2}$ concentration of $10 \mathrm{mmol} / \mathrm{L}$, the decoloration rate of CMR was as high as $50 \mu \mathrm{mol} \cdot \mathrm{min}^{-1} \cdot \mathrm{g}^{-1}$.
\end{abstract}

Keywords: bacterial cellulose; phthalocyanine; nanocomposite; catalytic membrane reactor

\section{Introduction}

Metal phthalocyanine complexes (MPcs) are very attractive as catalysts not only because they are structurally related to porphyrin complexes, but also due to their accessibility from a preparation point of view, as well as their chemical and thermal stability [1-4]. In practical applications, MPcs are often adsorbed, covalently-anchored, grafted, and encapsulated onto or into solid supports [5-11], which can offer better catalytic activity, the possibility for rapid separation from the reaction media, and feasible catalyst recycling for a continuous reaction, thus overcoming the formation of inactive aggregates [12,13], recoverability, and reusability limitations associated with free MPcs. The property of the support has a primary importance on the catalytic performance of MPc, thus choosing appropriate supporting material for MPc immobilization is considered a major challenge.

To improve the catalytic activity of MPc, a specific microenvironment provided by the support is essential. Several factors should be considered for the appropriate choice of the support: capacity to readily introduce functionality for anchoring, the degree of functionalization, the possible involvement with the reaction, the stability of the support under reaction conditions, and the availability of the support [1]. Among all of the supporting materials available for MPc immobilization, the bacterial cellulose (BC) membrane stands out due to several attractive characteristics [14-17]: it has a very large surface-to-volume ratio with easily tunable hydroxyls groups, thus, high MPc loading is, therefore, 
reasonably expected. It is produced in membrane form, the web-like network with a distinct tunnel and porous structure allowing the substrate to be readily accessible to reaction sites under very low diffusion resistance. In addition, BC is relatively stable under reaction conditions and is easily recoverable from the reaction media.

Among various practically-applied catalytic reaction technologies, catalytic membrane reactors (CMR) are subject of intensive studies [18-21]. CMR are structured reactors combining, in a single unit, a membrane that controls mass transfers, and a catalyst providing chemical activity [22-24]. With the combination of catalyst-immobilization and membrane technology, favorable synergic effects could be reasonably expected: the membrane contributes to the adequate performance of the continuous process, which greatly increases the surface accessibility and contact area between the heterogeneous catalyst and the substrate within a fixed volume. As a result, the efficiency of the catalytic reaction is substantially improved. In particular, constructing cellulose-based high-performance CMR is a field of growing interest [25-30].

In the present work, a $\mathrm{BC}$ membrane was employed for the immobilization of the tetra-amino cobalt (II) phthalocyanine (CoPc) catalyst. The BC was pre-oxidized by $\mathrm{NaIO}_{4}$ to generate aldehyde groups, to which CoPc-containing amino groups can be attached through covalent bonding. The extent of oxidation is well controlled prior to CoPc immobilization. A high-performance CMR was assembled with the prepared functional nanomaterial, CoPc immobilized BC nanocomposite (CoPc@BC). With reactive red $\mathrm{X}-3 \mathrm{~B}$ dye wastewater as the reaction model, the effects of operating parameters, that is, dye solution flow rate, operation temperature, and oxidant concentration on the performance of $\mathrm{CMR}$, was investigated. The electron paramagnetic resonance (EPR) technique was employed to reveal the mechanism of the catalytic oxidation process. It is expected that this work may provide better understanding for MPc immobilization, BC functionalization, and further application of CMR in industry.

\section{Materials and Methods}

\subsection{Materials and Reagents}

Acetobacter xylinum was purchased from BeNa Culture Collection Co., Ltd. (category No. BNCC336985; Beijing, China). Reactive red X-3B (C.I. Reative Red 2, $\mathrm{C}_{19} \mathrm{H}_{10} \mathrm{Cl}_{2} \mathrm{~N}_{6} \mathrm{Na}_{2} \mathrm{O}_{7} \mathrm{~S}_{2}, \mathrm{M}$.W.: 615.33) was purchased from Shanghai Chemical Reagent Factory (Shanghai, China). All other chemicals were of analytical grade and purchased from Sinopharm Chemical Reagent Co. Ltd. (Shanghai, China). Bacterial cellulose nanofibers were produced by cultivating the bacteria Acetobacter xylinum in a liquid culture medium containing $8.0 \mathrm{w} / \mathrm{v} \%$ D-glucose, $1.0 \mathrm{w} / \mathrm{v} \%$ yeast extract and $1.0 \mathrm{v} / \mathrm{v} \%$ ethanol, as reported in the literature [31]. Tetra-amino cobalt (II) phthalocyanine (CoPc) was synthesized from 4-nitrophthalic acid, urea, and cobalt chloride hexahydrate according to a method described previously [32,33]. The spin-trapping agent, 5,5-dimethyl-1-pyrroline- $N$-oxide (DMPO), was purchased from Sigma Chemical Co. (Saint Louis, MO, USA).

\subsection{Preparation of CoPc@BC}

To prepare CoPc@BC, the following steps were taken. First, $20 \mathrm{mg}$ of freeze-dried BC membrane was submerged into deionized water overnight, and then oxidized with $\mathrm{NaIO}_{4}$ solution at different concentrations elevated from $10 \mathrm{mmol} / \mathrm{L}$ to $50 \mathrm{mmol} / \mathrm{L}$, the oxidation process was performed in a shaking water bath. The oxidized BC membrane containing aldehyde groups was thoroughly washed by ultrapure water and dried at $60{ }^{\circ} \mathrm{C}$ under vacuum. The dried membrane was suspended in a $200 \mu \mathrm{mol} / \mathrm{L} \mathrm{CoPc}$ solution and reacted for $3 \mathrm{~h}$ at $25^{\circ} \mathrm{C}$, the product was washed several times with dimethylformamide (DMF) to eliminate residual $\mathrm{CoPc}$, and then rinsed three times with ultrapure water. All the schematic functionalization processes are given in Figure 1. The influence of different reaction parameters, i.e., $\mathrm{NaIO}_{4}$ concentration, oxidation time, and reaction temperature, on the immobilized amount of CoPc was systematically studied. The aldehyde groups' content on 
the oxidized BC was determined according to the literature, with minor modification [34,35]. An accurately-weighted $0.020 \mathrm{~g}$ oxidized $\mathrm{BC}$ was added to a $10 \mathrm{~mL}$ hydroxylamine hydrochloride solution at $50{ }^{\circ} \mathrm{C}$ for $2 \mathrm{~h}$ under stirring, the resulting mixture was titrated with $0.050 \mathrm{~mol} / \mathrm{L} \mathrm{HCl}$ solution with phenolphthalein as an indicator. A blank titration without oxidized BC was conducted under the same conditions. The aldehyde groups' content of the oxidized BC was calculated as follows:

$$
\text { Aldehyde content (wt./wt.\%) }=\frac{0.050 \mathrm{~mol} / L \times\left(V_{A}-V_{B}\right) m L \times 10^{-3} \times M W_{C O}}{0.020 g} \times 100
$$

where $V_{A}$ and $V_{B}$ are the consumed volumes of $\mathrm{HCl}$ solution for the blank and the sample, respectively. $M W_{C O}$ is the molecular weight of the carbonyl group.

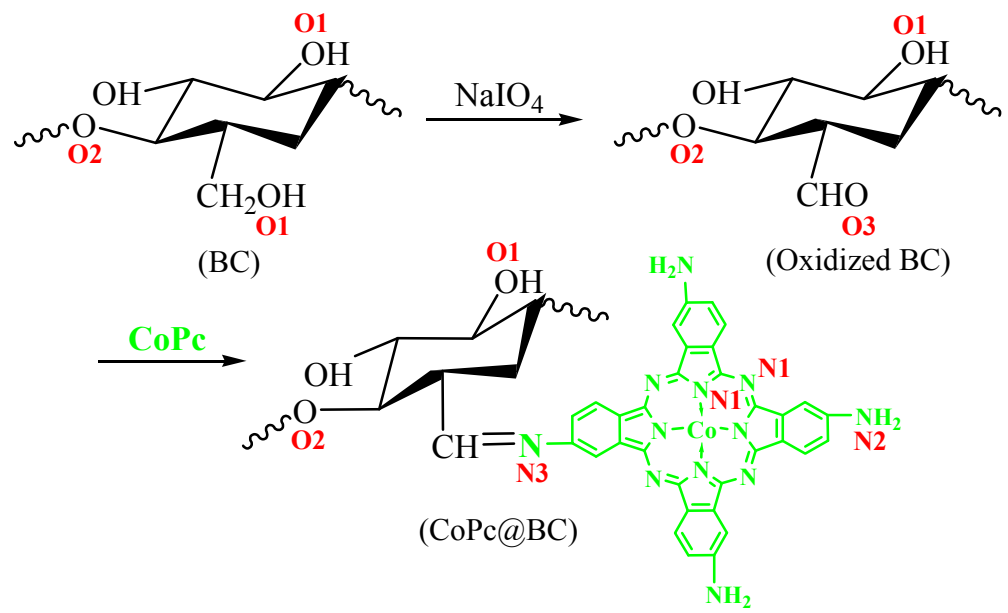

Figure 1. Synthesis route of $\mathrm{CoPc} @ \mathrm{BC}$.

The cobalt content on CoPc@BC was measured using microwave-assisted digestion flame atomic absorption spectroscopy (Thermo Sollar M6, Thermo Fisher, Waltham, MA, USA), allowing the calculation of the amount of CoPc immobilized onto the BC. The CoPc loading was defined as the amount of CoPc $(\mu \mathrm{mol})$ per gram of BC. Each value was the average of at least three separate experiments.

\subsection{Characterization}

Field emission scanning electron microscopy (FESEM, Serion, FEI, Hillsboro, OR, USA) was applied to observe the morphologies of the nanofibers. The surface compositions of the BC, oxidized $\mathrm{BC}$, and CoPc@BC were verified by attenuated total reflection Fourier transform infrared spectra (ATR/FT-IR). ATR/FT-IR spectra were acquired with a Vector 22 FTIR spectrometer (Brucker Optics, Faellanden, Switzerland) equipped with an ATR accessory (KRS-5 crystal, 45 ${ }^{\circ}$ in the $4000-400 \mathrm{~cm}^{-1}$ range. The resolution was fixed at $4 \mathrm{~cm}^{-1}$ and a total of 32 scans were accumulated for each spectrum. The elemental compositions and chemical bonding of the BC, oxidized BC, and CoPc@BC were analyzed by X-ray photoelectron spectroscopy (XPS). XPS spectra were recorded on a Kratos Axis Ultra XPS system with Al (mono) K $\alpha$ irradiation (hv=1486.6 eV). The cross-section of CoPc@BC after adsorption or catalytic oxidation was obtained by freezing the water-washed sample in liquid nitrogen and cracking with a blade. The binding energy peaks of the XPS spectra were calibrated by placing the principal C1s binding energy peak at $284.6 \mathrm{eV}$.

\subsection{Adsorption and Catalytic Oxidation Decoloration}

A CoPc@BC-based CMR was assembled for the decoloration of dye wastewater, and the experimental setup of the CMR is shown in Figure 2. In a typical adsorption experiment, the initial 
amount or concentration of a reaction mixture was controlled as follows: (a) $20 \mathrm{~mm}$ diameter and $14 \pm 1 \mu \mathrm{m}$ thick (ca. $1.60 \mathrm{mg}$ ) of CoPc@BC $(430 \pm 13 \mu \mathrm{mol} / \mathrm{g})$; and (b) $10 \mathrm{~mL}$ of reactive red X-3B solution $\left(100 \mu \mathrm{mol} / \mathrm{L}, 50{ }^{\circ} \mathrm{C}\right)$. The $\mathrm{pH}$ value of the dye solution was adjusted with $\mathrm{H}_{2} \mathrm{SO}_{4}$ or $\mathrm{NaOH}$. The adsorption was investigated by the concentration of reactive red $\mathrm{X}-3 \mathrm{~B}$, which is proportional to its absorbance at $539 \mathrm{~nm}$, as monitored by a UV-VIS absorption spectrometer UV-2450. The concentration change of reactive red $X-3 B$ was express as the change of $C / C_{0}$ value, where $C_{0}$ is the initial concentration of the dye, and $C$ is the residual concentration of the dye.

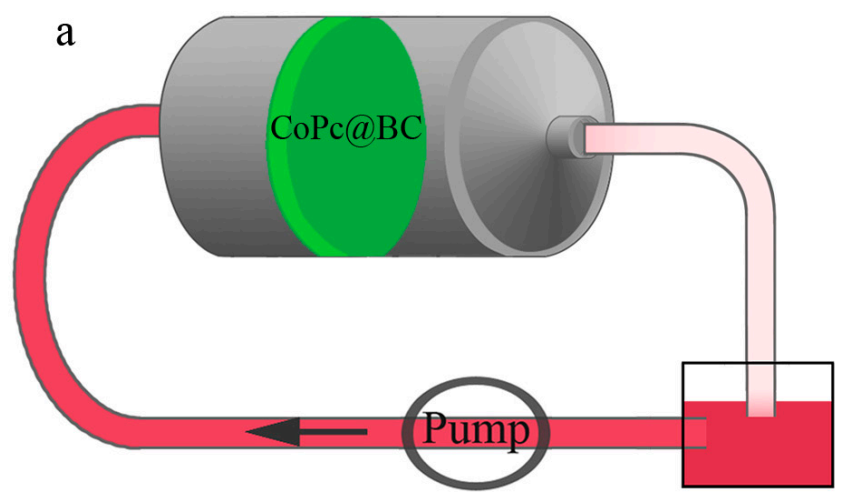

b

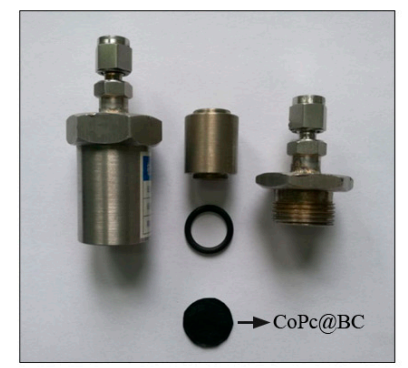

Figure 2. (a) Schematic representation of the CoPc@BC-based catalytic membrane reactor (CMR); (b) Optical image of the CoPc@BC-based CMR.

For the initiation of the catalytic oxidation process, a required amount of $\mathrm{H}_{2} \mathrm{O}_{2}$ was added into the above mentioned adsorption system. The measurement method for catalytic oxidation decoloration is the same as that of adsorption process, the decoloration rate of $\mathrm{CoPc} @ \mathrm{BC}$ (CoPc loading: $430 \pm 13 \mu \mathrm{mol} / \mathrm{g}$ ) was calculated using Equation (2):

$$
\text { Decoloration rate }\left(\mu \mathrm{mol} \cdot \mathrm{min}^{-1} \cdot \mathrm{g}^{-1}\right)=\frac{100 \mu \mathrm{mol} / \mathrm{L} \times 10 \times 10^{-3} \mathrm{~L} \times 90 \%}{t \mathrm{~min} \times 1.60 \times 10^{-3} \mathrm{~g} \times 430 \times 10^{-6} \mathrm{~mol} / \mathrm{g} \times 630 \mathrm{~g} / \mathrm{mol}}
$$

where $t$ is the time for decoloration of $90 \%$ of reactive red X-3B. EPR signal of radical spin-trapped by DMPO was detected with a Bruker-A300 X-band EPR spectrometer (Bruker, Karlsruhe, Germany). For every run in the cyclic utilizations, CoPc@BC was taken out, rinsed with ultrapure water, and dried at $25{ }^{\circ} \mathrm{C}$ for $12 \mathrm{~h}$ under vacuum.

\section{Results and Discussion}

\subsection{Characterization}

Treating the cellulose nanofibers with $\mathrm{NaIO}_{4}$ is a well-established method for the generation of aldehyde groups, which can be potentially exploited as the binding sites for the immobilization of functional molecules [35,36]. Herein, the CoPc@BC nanocomposite was prepared by the covalent reaction of the amino groups on $\mathrm{CoPc}$ with the aldehyde groups on the oxidized $\mathrm{BC}$. The results of the characterization study of the functionalization processes were given in our previous study and were used in the present study whenever it was necessary [16]. FESEM shows that the total nanofiber structure of the CoPc@BC nanocomposite was well maintained after functionalization (Figure S1, Supplementary Materials). ATR/FT-IR spectroscopy was adopted to monitor the progress of the surface modification reactions [16], as was shown in Figure S2. The strong absorption in the range of 3200-3500 $\mathrm{cm}^{-1}$ attributed to the vibration of the hydroxyl groups in the biosynthesized BC (Figure S2a). For the oxidized BC, the observation of a new characteristic peak at $\sim 1650 \mathrm{~cm}^{-1}$ verified the success of oxidation process and the formation of the aldehyde groups on the surface of BC (Figure S2b). The expected appearance of a new absorption peak at $\sim 1610 \mathrm{~cm}^{-1}\left(v_{\mathrm{C}=\mathrm{N}}\right.$ of CoPc) 
and the significant decrease of the characteristic peak at $\sim 1650 \mathrm{~cm}^{-1}$ confirmed the successful reaction of the aldehyde groups and the immobilization of the CoPc molecules onto the BC (Figure S2c).

XPS was also performed to analyze the chemical composition of the $\mathrm{BC}$ surface during the series of modification [16]. For the as-prepared BC (Figure 3a), the two characteristic peaks at $284.6 \mathrm{eV}$ and $533 \mathrm{eV}$ were ascribed to the binding energy of $\mathrm{C} 1 \mathrm{~s}$ and $\mathrm{O} 1 \mathrm{~s}$, respectively. The oxidation process did not significantly change the XPS spectrum of the BC membrane (Figure 3b). Upon the immobilization of $\mathrm{CoPc}$ molecules onto the oxidized $\mathrm{BC}$, an additional new peak at a binding energy of ca. $400 \mathrm{eV}$ was observed (Figure 3c), which was the characteristic peak of $\mathrm{N}_{1 \mathrm{~s}}$. Furthermore, two new signals at binding energy of $779.1 \mathrm{eV}$ and $793.9 \mathrm{eV}$ were also detected (Figure 3, inset), which were assigned to the characteristic peaks of $\mathrm{Co}_{0} 2 \mathrm{p}_{3 / 2}$ and $\mathrm{Co} 2 \mathrm{p}_{1 / 2}$, respectively. These results provide further evidence for the immobilization of CoPc onto BC and the successful preparation of CoPc@BC.

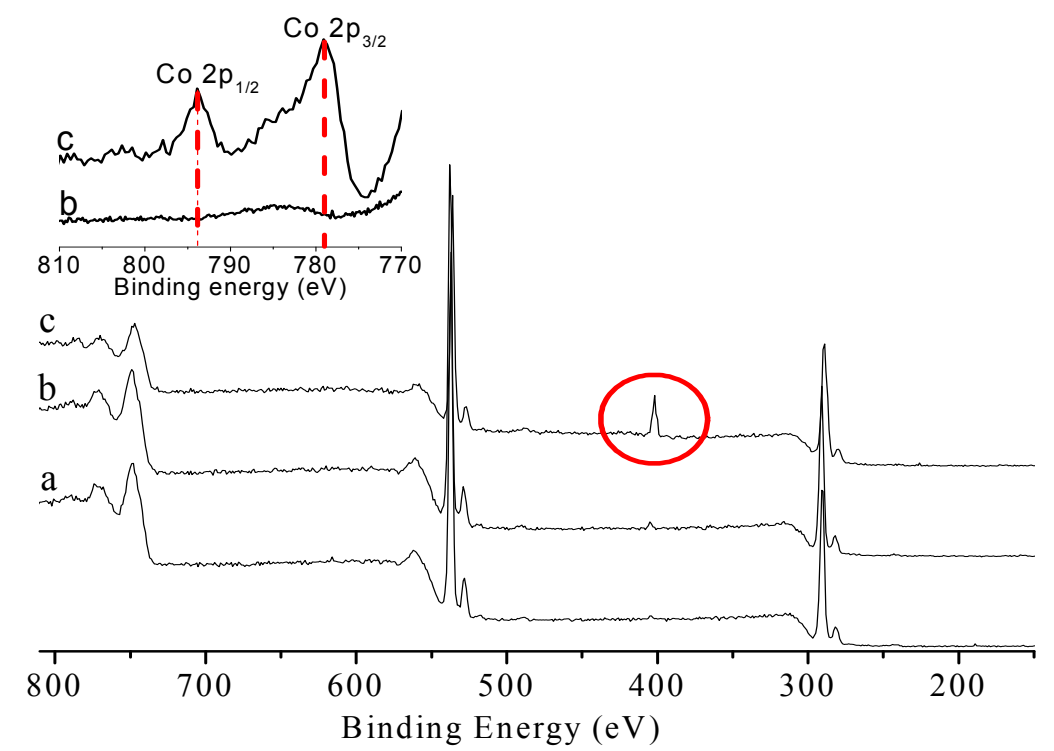

Figure 3. XPS spectra of (a) BC; (b) oxidized BC; and (c) CoPc@BC. The window included shows, in detail, the Co region.

The high-resolution O1s peaks and N1s peaks in the XPS spectra of nanofiber mats gives detailed information on $\mathrm{O}$ and $\mathrm{N}$ chemistry during the functionalization processes (Figure 4). For pure BC, the $\mathrm{O} 1$ s peak centered at $532.5 \mathrm{eV}$ was ascribed to $\mathrm{C}-\mathrm{OH}(\mathrm{O} 1, \mathrm{BC}$ of Figures 1 and 4a), and the O1s peak occurring at $533.1 \mathrm{eV}$ was due to $\mathrm{C}-\mathrm{O}-\mathrm{C}(\mathrm{O} 2, \mathrm{BC}$ of Figures 1 and 4a) [37]. For oxidized BC, besides the detection of $\mathrm{O} 1$ and $\mathrm{O} 2$, the new $\mathrm{O} 1$ s peak present at $532.1 \mathrm{eV}$ was assigned to $\mathrm{C}=\mathrm{O}(\mathrm{O} 3$, oxidized $\mathrm{BC}$ of Figures 1 and $4 b$ ), implying the successful formation of aldehyde groups. The proportion of $C=O$ peak is smaller in $\mathrm{CoPc} @ \mathrm{BC}$ than that of oxidized BC, indicating that a part of aldehyde groups were reacted with $\mathrm{CoPc}(\mathrm{O} 3$, Figure 4c). The remaining existence of aldehyde groups was likely due to the steric hindrance effect for the immobilization and the incompleteness character of macromolecular reaction.

Furthermore, the N1s peaks give detailed information of the bonding environment of CoPc@BC (Figure 4d). The N1s peaks present at $398.8 \mathrm{eV}$ and $399.8 \mathrm{eV}$ were described to aza-bridging nitrogen, pyrrole nitrogen (N1, CoPc@BC of Figures 1 and 4d), and nitrogen of peripheral amino groups (N2, CoPc@BC of Figures 1 and $4 \mathrm{~d}$ ), respectively [38,39]. In addition, the peak at $400.5 \mathrm{eV}$ was assigned to the nitrogen of $-\mathrm{C}=\mathrm{N}-(\mathrm{N} 3, \mathrm{CoPc} @ \mathrm{BC}$ of Figures 1 and $4 \mathrm{~d})$, which was the reaction product of aldehyde groups of the oxidized $\mathrm{BC}$ and amino groups of $\mathrm{CoPc}$. These results provided clear evidence for successful modification and covalent immobilization of CoPc on BC. 

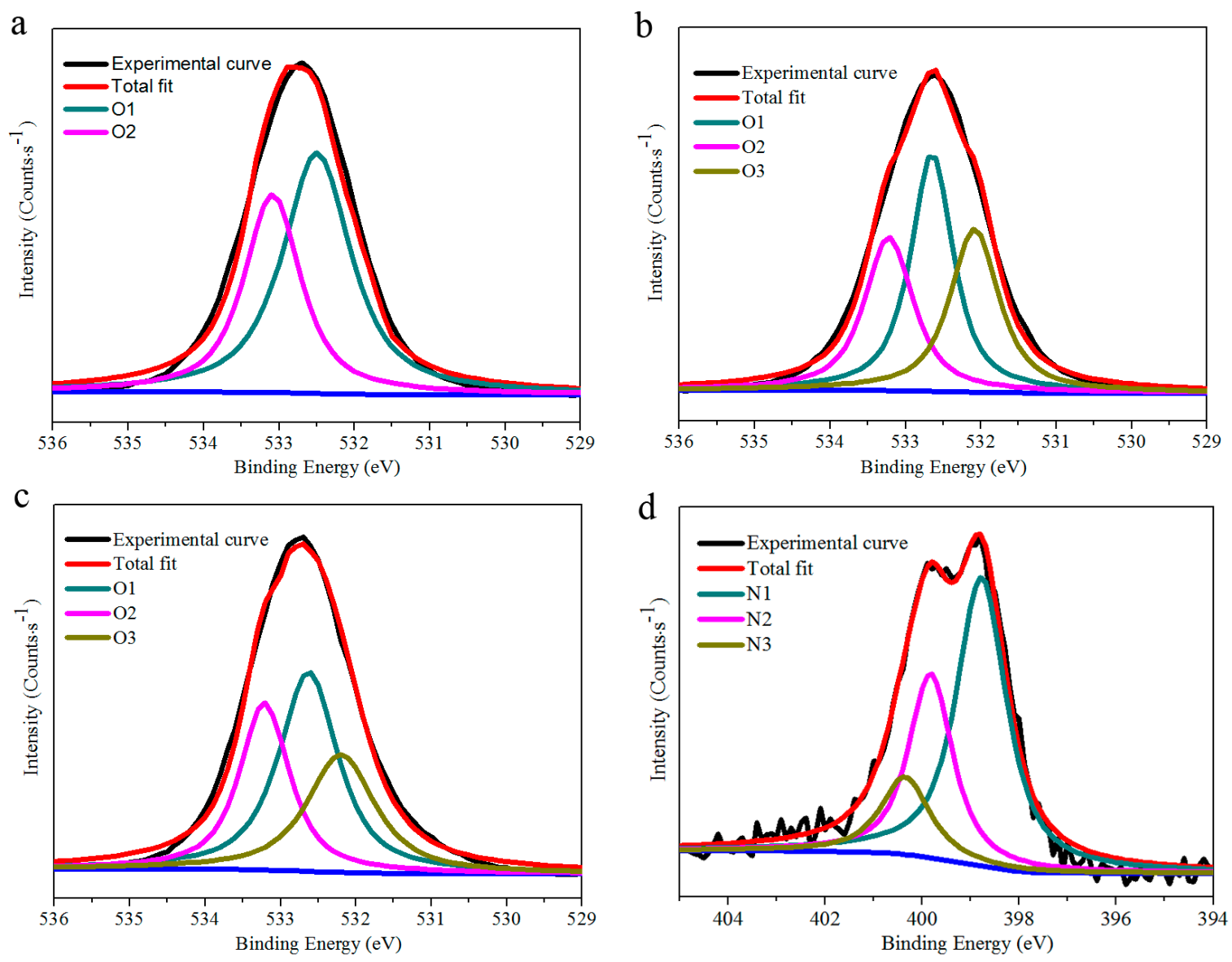

Figure 4. Curve fit of (a) O1s peaks of BC; (b) O1s peaks of oxidized BC; (c) O1s peaks of CoPc@BC; and (d) N1s peaks of CoPc@BC.

\subsection{Optimization of Immobilization Conditions}

For possible industrial application, high CoPc loading is desired to reduce the size of reactor and enhance the efficiency of catalytic reaction; hence, the content of aldehyde groups should be maximized. In this study, three parameters $\left(\mathrm{NaIO}_{4}\right.$ concentration, oxidation temperature, and oxidation time) describing different oxidation conditions with the corresponding CoPc loading were carefully studied.

The effect of $\mathrm{NaIO}_{4}$ concentration on the CoPc loading was assayed within the concentration range from $10 \mathrm{mmol} / \mathrm{L}$ to $45 \mathrm{mmol} / \mathrm{L}$, and the typical result is shown in Figure 5 . Both the aldehyde groups' content and the CoPc loading increased rapidly with $\mathrm{NaIO}_{4}$ concentration. To provide more binding sites for CoPc immobilization, a sufficient amount of oxidizer $\left(\mathrm{NaIO}_{4}\right)$ must be applied to maximize the yield of the aldehyde groups. The CoPc loading was less than $200 \mu \mathrm{mol} / \mathrm{g}$ with $10 \mathrm{mmol} / \mathrm{L}$ $\mathrm{NaIO}_{4}$. When $\mathrm{NaIO}_{4}$ concentration increased to $30 \mathrm{mmol} / \mathrm{L}$, the aldehyde groups' content of the oxidized BC increased from 5 to $14 \mathrm{wt}$./wt.\% and, accordingly, the CoPc loading was as high as $430 \mu \mathrm{mol} / \mathrm{g}$. However, a further increase of $\mathrm{NaIO}_{4}$ concentration results in the slow decrease of CoPc loading. This phenomenon can be attributed to two reasons. Firstly, under a very high concentration of $\mathrm{NaIO}_{4}$, a portion of the formed aldehyde groups were likely to further oxidize to carboxyl groups [40], reducing the binding sites which can readily react with CoPc, thus leading to a slightly lower level of CoPc loading. This result is in accordance with the gradual decrease of the aldehyde groups' content under very high $\mathrm{NaIO}_{4}$ concentrations (Figure 5). The second explanation is related to the gradual degradation of cellulose chains with the high concentration of $\mathrm{NaIO}_{4}$ [36], which is quite possible for the very large surface to volume ratio of BC. 


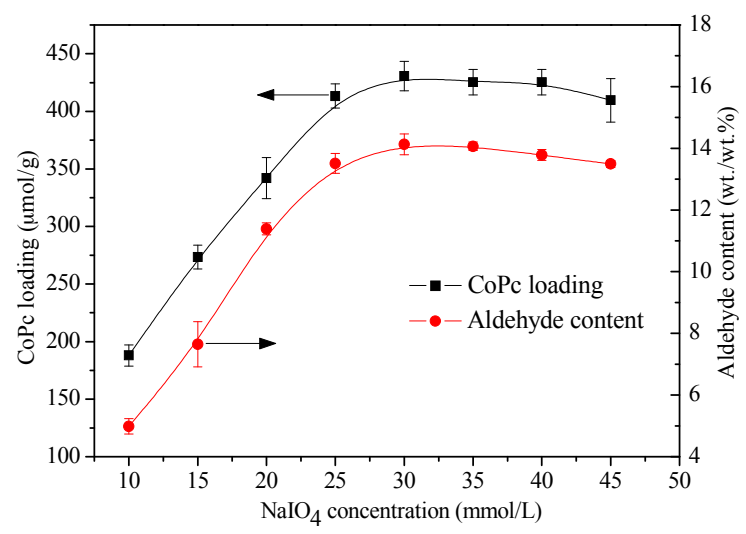

Figure 5. Effect of $\mathrm{NaIO}_{4}$ concentration on CoPc loading of CoPc@BC (filled square) and aldehyde content of $\mathrm{BC}$ (filled circle), $\mathrm{T}=30^{\circ} \mathrm{C}$, reaction time $=8 \mathrm{~h}$.

An increased temperature range from $10{ }^{\circ} \mathrm{C}$ to $45^{\circ} \mathrm{C}$ was applied to study the effect of oxidation temperature on the CoPc loading. As shown in Figure S3, both the aldehyde content and the CoPc loading increased rapidly with the oxidation temperature, CoPc@BC with ca. $430 \mu \mathrm{mol} / \mathrm{g}$ of CoPc was obtained at $30^{\circ} \mathrm{C}$. Above this temperature, the CoPc loading of $\mathrm{BC}$ decreased gradually. A similar result was also found for the investigation of the influence of oxidation time on the aldehyde content and the CoPc loading (Figure S4). These results can also be explained by the reason discussed above. With the increase of oxidation temperature and oxidation time, more aldehyde groups were formed correspondingly on $\mathrm{BC}$, that is, more binding sites were generated for CoPc immobilization. However, one should note that the transformation of the aldehyde groups to the carboxyl groups was possible with very high oxidation temperature and further elongation of oxidation time.

Therefore, a $\mathrm{NaIO}_{4}$ concentration of $30 \mathrm{mmol} / \mathrm{L}$, an oxidation temperature of $30^{\circ} \mathrm{C}$, as well as an oxidation time of $8 \mathrm{~h}$ was chosen for the oxidation of $\mathrm{BC}$, and the resulting oxidized $\mathrm{BC}$ contains $14.13 \%$ (wt./wt.) of the aldehyde groups, which is slightly lower than the theoretical maximum content of $18.1 \%$ (wt./wt.). The relatively low yield of aldehyde groups can be ascribed to the difficulty of heterogeneous reaction and the incompletion of macromolecular reaction. Under the optimal oxidation conditions, a CoPc@BC with $430 \pm 13 \mu \mathrm{mol} / \mathrm{g}$ of CoPc was prepared, indicating the high reliability of this technique for the immobilization of CoPc.

\subsection{Adsorption of Dye Molecules on CoPc@BC}

The prepared CoPc@BC nanocomposite was aimed as a functional nanomaterial for the catalytic oxidation of organic pollutants, with reactive red $\mathrm{X}-3 \mathrm{~B}$ dye wastewater as a model contaminant. For a heterogeneous catalyst, the catalytic reaction mainly consists of two parts: the adsorption of the substrate onto the solid and the following degradation reaction of the adsorbed substrate [41]. Thus, the interaction between the $\mathrm{CoPc} @ \mathrm{BC}$ catalyst and the dye substrate is indispensable for the efficient catalytic oxidation reaction. Both the surface character of CoPc@BC and the property of the dye molecules have a great effect on this interaction. Herein, by monitoring the concentration change of reactive red $\mathrm{X}-3 \mathrm{~B}$ in the bulk solution, the influence of $\mathrm{pH}$ value on the adsorption behavior of CoPc@BC was firstly investigated (Figure 6a). The decrease of the dye concentration demonstrates the gradual adsorption of dye molecules onto the heterogeneous catalyst. When the adsorption reached a dynamic equilibrium, the dye concentration remains at a certain level and does not decrease with a further elongation of time. It was found that both the adsorption rate and the saturated adsorption amount were significantly increased with the decline of $\mathrm{pH}$. The saturated adsorption amount was $66 \%$ at $\mathrm{pH} 2$, compared with $50 \%$ at $\mathrm{pH} 4$ and $30 \%$ at $\mathrm{pH} 6$. The highly-saturated adsorption amount of CoPc@BC under acidic conditions is derived from the strong electrostatic interaction between the $\mathrm{CoPc}$ molecules on the nanocomposite and the dye molecules. The amino groups of CoPc molecules 
can function as an "antenna" to accept a proton from the acidic solution, endowing the surface of CoPc@BC with positive charges, which can be preferably adsorbed by the anionic dye molecules to a considerable extent via electrostatic interaction with the sulfonic groups of the reactive red X-3B.
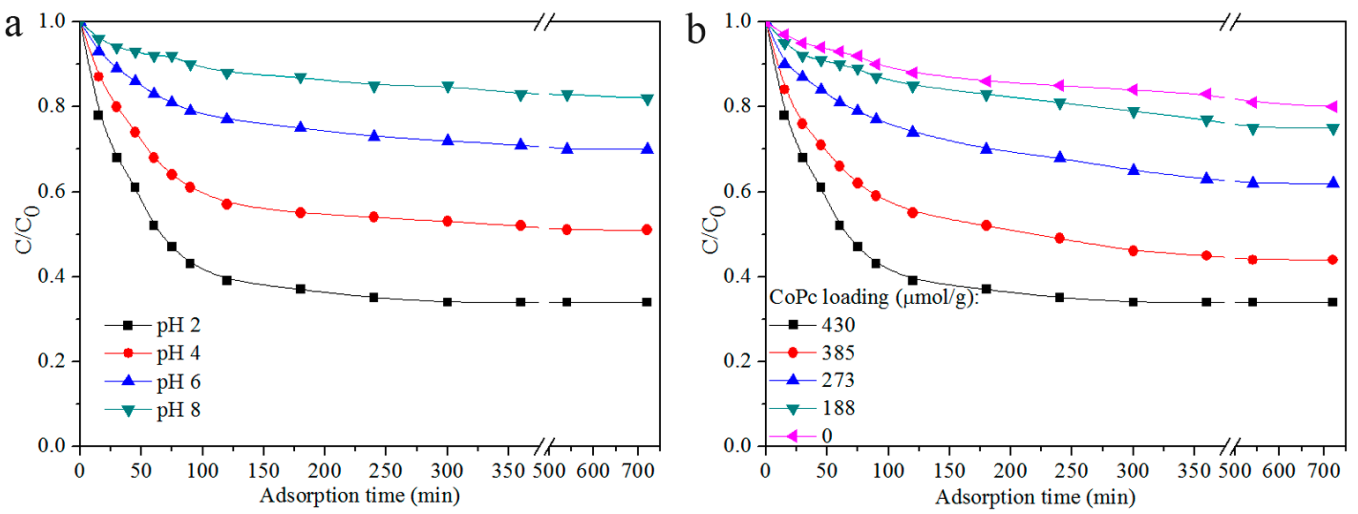

Figure 6. Concentration changes of reactive red $\mathrm{X}-3 \mathrm{~B}$ (initial concentration: $1 \times 10^{-4} \mathrm{~mol} / \mathrm{L}, \mathrm{T}=50^{\circ} \mathrm{C}$ ) with CoPc@BC (1.60 mg) adsorption: (a) effect of pH; and (b) the effect of CoPc loading.

The influence of CoPc loading on the adsorption process was also investigated (Figure 6b). It is obvious that the increase of CoPc loading can efficiently increase both the adsorption rate and the saturated adsorption amount of dye molecules. The increased "antenna" CoPc molecules reasonably increased the proton accepting ability of CoPc@BC nanocomposite, which results in its enhanced dye adsorption ability. Thanks to the very large surface-to-volume ratio of BC, the CoPc loading was much higher comparing with that of traditional solid supports, thus, the saturated adsorption amount of CoPc@BC nanocomposite is, accordingly, very high.

The composition of CoPc@BC, both in cross-section and on the surface after dye adsorption, was studied with XPS, and the results are shown in Figure 7 and Figure S5, respectively. Compared with the original CoPc@BC (Figure 3c), two new signals at binding energies of $163.5 \mathrm{eV}$ and $167.9 \mathrm{eV}$ were assigned to the characteristic peaks of $S 2 p_{3 / 2}$ and $S 2 p_{1 / 2}$, respectively (Figure 7 and Figure S5, right inset). The new signals at binding energies of $200 \mathrm{eV}$ and $202 \mathrm{eV}$ were ascribed to the characteristic peaks of $\mathrm{Cl} 2 \mathrm{p}_{3 / 2}$ and $\mathrm{Cl} 2 \mathrm{p}_{1 / 2}$, respectively (Figure 7 and Figure S5, middle inset). The detection of these two elements implies that the adsorption occurs not only on the surface, but also in the deep interior of CoPc@BC. Thanks to the highly three-dimensional porous network structure, the contact between the CoPc catalyst and dye molecules is more effective than other supports, which is quite important for the subsequent catalytic oxidation.

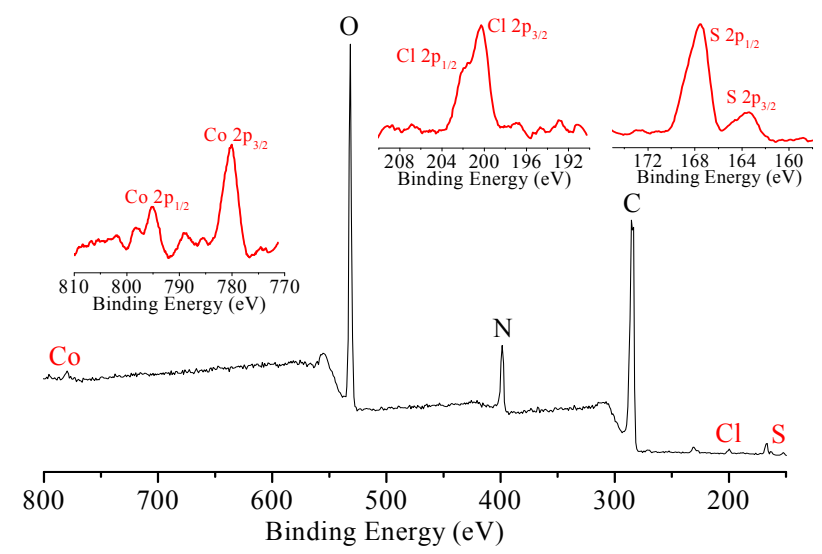

Figure 7. XPS of the cross-section of CoPc@BC after dye adsorption. Left inset: detail of the Co region, middle inset: detail of the $\mathrm{Cl}$ region; and right inset: detail of the $\mathrm{S}$ region. 


\subsection{Catalytic Oxidation Studies under Various Operational Conditions}

The performance of $\mathrm{CMR}$ assembled with $\mathrm{CoPc} @ \mathrm{BC}$ is evaluated in terms of the catalytic oxidation efficiency of reactive red X-3B, with $\mathrm{H}_{2} \mathrm{O}_{2}$ as an oxidant. To explicitly show how CoPc@BC affects the catalytic oxidation reaction, blank experiments were performed under $\mathrm{H}_{2} \mathrm{O}_{2}$ oxidation without the addition of the CoPc@BC catalyst. Almost no color change can be detected after $4 \mathrm{~h}$ with the existence of $\mathrm{H}_{2} \mathrm{O}_{2}$ (data not shown), indicating that CoPc@BC is indispensible for the catalytic oxidation reaction. Figure 8 shows the decoloration of the dye solution with time under various flow rates. The rapid decrease of dye concentration indicates that the catalytic oxidation reaction occurring during the operation, and the decoloration rate depends strongly on the dye solution flow rate (Figure 8, inset). The decoloration rate was ca. $50 \mu \mathrm{mol} \cdot \mathrm{min}^{-1} \cdot \mathrm{g}^{-1}$ when the dye solution flow rate was set to $6 \mathrm{~mL} / \mathrm{min}$, comparing with ca. $20 \mu \mathrm{mol} \cdot \mathrm{min}^{-1} \cdot \mathrm{g}^{-1}$ at flow rate of $2 \mathrm{~mL} / \mathrm{min}$. A higher flow rate can effectively decrease the mass transfer resistance of dye molecules and $\mathrm{H}_{2} \mathrm{O}_{2}$ to the CoPc@BC nanocomposite, increasing both the contact opportunity and the contact frequency among the reactant dye molecules, $\mathrm{H}_{2} \mathrm{O}_{2}$, and the heterogeneous CoPc@BC catalyst. In this way, the catalytic oxidation rate of dye molecules was effectively increased. However, a further increase of the dye solution flow rate does not consistently result in the increase of the decoloration rate. This is possibly due to the shorter contact time between the CoPc@BC and the reactants at too high a flow rate, thus, the dye molecules cannot be sufficiently catalytic oxidized by $\mathrm{CoPc} @ B C / \mathrm{H}_{2} \mathrm{O}_{2}$ reaction system. In this regard, we chose $6 \mathrm{~mL} / \mathrm{min}$ as the optimal dye solution flow rate.

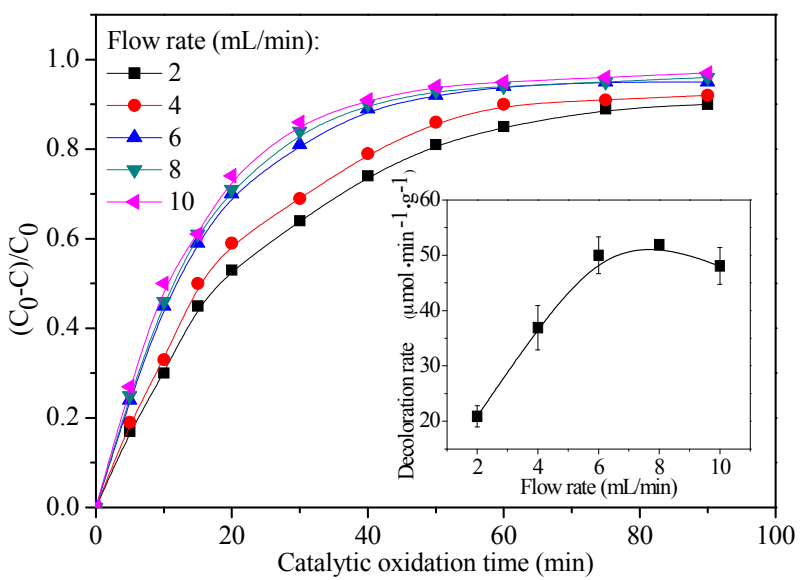

Figure 8. Typical concentration changes of reactive red $\mathrm{X}-3 \mathrm{~B}\left(\mathrm{~T}=50^{\circ} \mathrm{C}, \mathrm{pH}=2\right)$ with CoPc@BC $(1.60 \mathrm{mg})$ and $\mathrm{H}_{2} \mathrm{O}_{2}(10 \mathrm{mmol} / \mathrm{L})$ under various flow rates. Inset: Effect of flow rate on the decoloration rate of reactive red $\mathrm{X}-3 \mathrm{~B}$.

The effect of the reaction temperature on the catalytic oxidation performance of CMR is shown in Figure S6. Reactive red X-3B dye wastewater is able to be catalytically oxidized over a broad temperature range. The catalytic oxidation rate increased with the reaction temperature, while only a slight increase in the reaction rate can be achieved when the reaction temperature is higher than $50{ }^{\circ} \mathrm{C}$. Higher temperatures cause a greater chance of self-decomposition of $\mathrm{H}_{2} \mathrm{O}_{2}$. Considering both the catalytic oxidation efficiency and the minimization of energy consumption, the optimal operational temperature was set to $50^{\circ} \mathrm{C}$.

Figure S7 shows the decoloration rate as a function of $\mathrm{H}_{2} \mathrm{O}_{2}$ concentration. It is conceivable that a relatively higher catalytic oxidation rate could be obtained by increasing the concentration of the $\mathrm{H}_{2} \mathrm{O}_{2}$ oxidant during the reaction. The catalytic oxidation rate was ca. $50 \mu \mathrm{mol} \cdot \mathrm{min}^{-1} \cdot \mathrm{g}^{-1}$ with the addition of $10 \mathrm{mM} \mathrm{H}_{2} \mathrm{O}_{2}$, comparesd with ca. $20 \mu \mathrm{mol} \cdot \mathrm{min}^{-1} \cdot \mathrm{g}^{-1}$ when the $\mathrm{H}_{2} \mathrm{O}_{2}$ concentration is $6 \mathrm{mM}$. A slight reaction rate change was observed when the $\mathrm{H}_{2} \mathrm{O}_{2}$ concentration was higher than $10 \mathrm{mM}$. In this regard, we chose $10 \mathrm{mM} \mathrm{H}_{2} \mathrm{O}_{2}$ as the optimal oxidant concentration. 
Therefore, a flow rate of $6 \mathrm{~mL} / \mathrm{min}$, together with the reaction temperature of $50{ }^{\circ} \mathrm{C}$ and $\mathrm{H}_{2} \mathrm{O}_{2}$ concentration of $10 \mathrm{mM}$, were required for this high-performance CMR. Under these optimal operating conditions, the decoloration rate of the CMR was ca. $50 \mu \mathrm{mol} \cdot \mathrm{min}^{-1} \cdot \mathrm{g}^{-1}$. The catalytic oxidation efficiency of the present CMR is much higher compared with the related literature we reported previously [32,42].

The composition of cross-section of CoPc@BC after catalytic oxidation was analyzed with XPS (Figure 9). The two peaks corresponding to $\mathrm{Co}_{2} 2 \mathrm{p}_{3 / 2}$ and $\mathrm{Co}_{2} 2 \mathrm{p}_{1 / 2}$ remains can be detected after reaction. However, almost no signal was observed in the range of binding energy between $210 \mathrm{eV}$ and $160 \mathrm{eV}$ (the position of characteristic peaks of $\mathrm{S}$ and $\mathrm{Cl}$ ), which indirectly verified that the adsorbed dye molecules were successfully catalytically oxidized. A similar result was obtained for the XPS of the surface composition of CoPc@BC (data not shown).

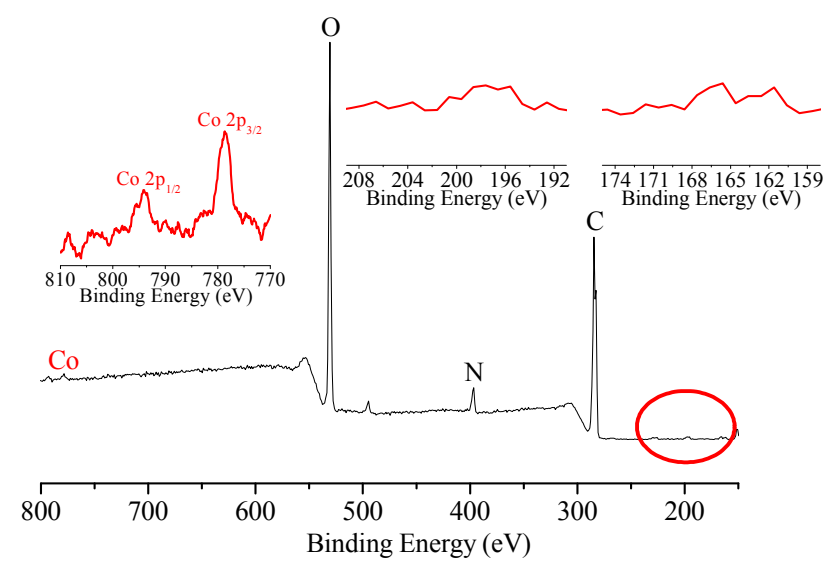

Figure 9. XPS of cross-section of CoPc@BC after catalytic oxidation. Left inset: detail of Co region, middle inset: detail of $\mathrm{Cl}$ region, right inset: detail of $\mathrm{S}$ region.

The EPR spin-trapping technique was applied to monitor the formation of reactive species which are responsible for the catalytic oxidation of reactive red X-3B by CoPc@BC/ $/ \mathrm{H}_{2} \mathrm{O}_{2}$ reaction system. As shown in Figure 10, no signal was observed without the addition of $\mathrm{H}_{2} \mathrm{O}_{2}$. However, obvious signals with four peaks were generated when $10 \mathrm{mM}$ of $\mathrm{H}_{2} \mathrm{O}_{2}$ was added, which are the typical characteristic peaks of DMPO-OH adducts [43], indicating the involvement of highly-reactive $\cdot \mathrm{OH}$ during the catalytic oxidation process.

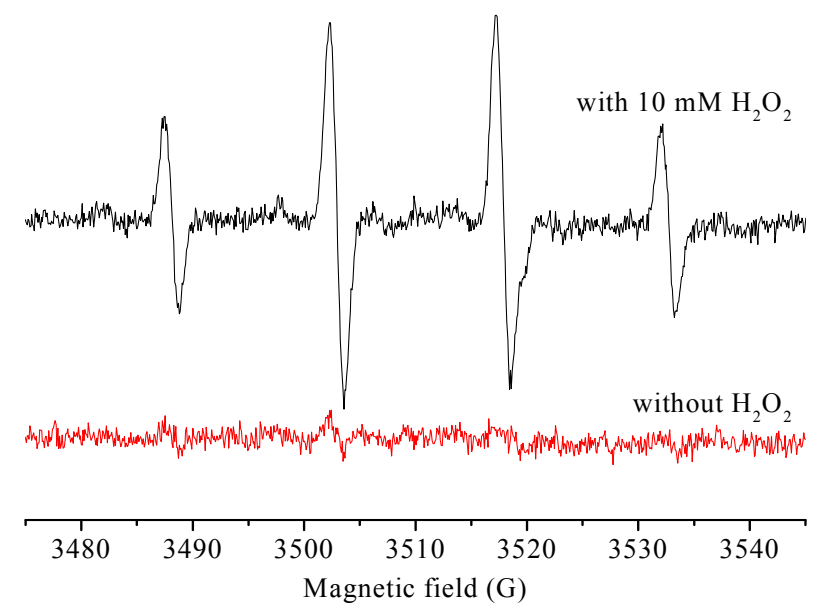

Figure 10. DMPO spin-trapping EPR spectra of reactive red $\mathrm{X}-3 \mathrm{~B}$ dye solution (initial concentration: $\left.1 \times 10^{-4} \mathrm{~mol} / \mathrm{L}, \mathrm{CoPc} @ B C: 1.60 \mathrm{mg}, \mathrm{T}=50^{\circ} \mathrm{C}\right)$. 
In practical applications, the stability and the recyclability of the catalyst should be taken into account. The catalytic activity of CoPc@BC in cyclic utilizations was investigated, and no significant decrease of catalytic efficiency was found (Figure S8). The catalytic activity of CoPc@BC remained excellent after recycling five times. No CoPc absorbance peak (in the range of 600-800 nm) was detected during the reaction. These results indicate that the $\mathrm{CoPc} @ B C / \mathrm{H}_{2} \mathrm{O}_{2}$ reaction system is recyclable for consecutive catalytic oxidation of dye wastewater, which is desirable for industrial applications.

On the basis of the results above, a proposed mechanism of catalytic oxidation of dye molecules with the CoPc@BC/ $\mathrm{H}_{2} \mathrm{O}_{2}$ reaction system is presented in Figure 11. $\mathrm{H}_{2} \mathrm{O}_{2}$ was catalyzed by CoPc@BC to form highly-reactive hydroxyl radicals, and the produced $\mathrm{OH}$ will attack the adsorbed dye molecules which were "anchored" by the CoPc "antenna". The high CoPc loading of CoPc@BC allows the easily adsorption of dye molecules, and the circulation system of CMR can effectively promote the formation of $\cdot \mathrm{OH}$ and the further catalytic oxidation of the adsorbed dye, thus, the catalytic efficiency was substantially improved.

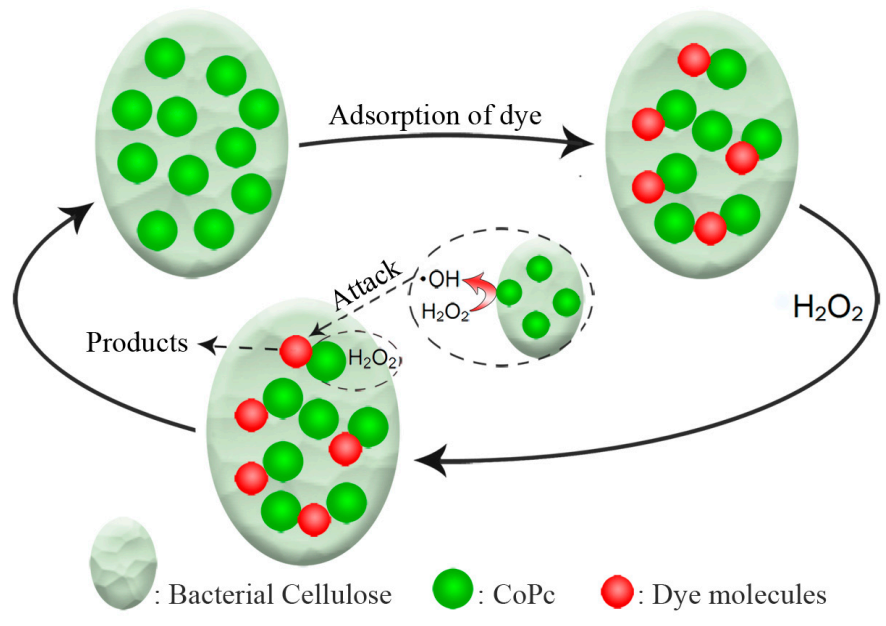

Figure 11. Conceptual representation of catalytic oxidation of reactive red X-3B with CoPc@BC/ $\mathrm{H}_{2} \mathrm{O}_{2}$ reaction system.

\section{Conclusions}

In the current research, we have systematically quantified the immobilization of CoPc onto BC for the fabrication of CoPc-immobilized BC nanocomposite, CoPc@BC. The optimal processing conditions are as follows: $\mathrm{NaIO}_{4}$ concentration of $30 \mathrm{mmol} / \mathrm{L}$, an oxidation temperature of $30^{\circ} \mathrm{C}$, and an oxidation time of $8 \mathrm{~h}$. The potential ability of $\mathrm{CoPc} @ \mathrm{BC}$ for the removal of dye wastewater was thoroughly investigated, the saturated adsorption amount of CoPc@BC increased with the decrease of $\mathrm{pH}$ and the increase of CoPc loading. A catalytic membrane reactor (CMR) assembling with CoPc@BC was designed and operated. Under optimal operating conditions of a dye solution flow rate of $6 \mathrm{~mL} / \mathrm{min}$, a reaction temperature of $50{ }^{\circ} \mathrm{C}$, and an $\mathrm{H}_{2} \mathrm{O}_{2}$ concentration of $10 \mathrm{mmol} / \mathrm{L}$, the decoloration rate of $\mathrm{CMR}$ was as high as $50 \mu \mathrm{mol} \cdot \mathrm{min}^{-1} \cdot \mathrm{g}^{-1}$. EPR spectral results revealed that $\cdot \mathrm{OH}$ is responsible for the catalytic oxidation of dye molecules.

Supplementary Materials: The following are available online at www.mdpi.com/1996-1944/10/7/846/s1. Figure S1. FESEM of (a) pure BC, and (b) CoPc@BC; Figure S2. ATR/FT-IR spectra of (a) BC, (b) oxidized BC, and (c) CoPc@BC; Figure S3. Effect of oxidation temperature on CoPc loading of CoPc@BC (filled square) and aldehyde content of BC (filled circle); Figure S4. Effect of oxidation time on CoPc loading of CoPc@BC (filled square) and aldehyde content of BC (filled circle); Figure S5. XPS of surface of CoPc@BC after dye adsorption. Left inset: detail of Co region, middle inset: detail of $\mathrm{Cl}$ region, right inset: detail of $\mathrm{S}$ region; Figure S6. Effect of reaction temperature on decoloration rate of reactive red X-3B (flow rate: $6 \mathrm{~mL} / \mathrm{min}, \mathrm{H}_{2} \mathrm{O}_{2}$ concentration: $10 \mathrm{mmol} / \mathrm{L}$ ); Figure S7. Effect of initial $\mathrm{H}_{2} \mathrm{O}_{2}$ concentration on decoloration rate of reactive red X-3B (flow rate: $6 \mathrm{~mL} / \mathrm{min}, \mathrm{T}=50{ }^{\circ} \mathrm{C}$ ); Figure $\mathrm{S} 8$. Repetitive catalytic oxidation of reactive red $\mathrm{X}-3 \mathrm{~B}$ (initial concentration: $1 \times 10^{-4} \mathrm{~mol} / \mathrm{L}$, CoPc@BC: $1.60 \mathrm{mg}$, flow rate: $6 \mathrm{~mL} / \mathrm{min}, \mathrm{H}_{2} \mathrm{O}_{2}$ concentration: $\left.10 \mathrm{mmol} / \mathrm{L}, \mathrm{T}=50^{\circ} \mathrm{C}\right)$ for $60 \mathrm{~min}$. 
Acknowledgments: This work was supported by the Zhejiang Provincial Natural Science Foundation of China (grant no. LQ15E030005).

Author Contributions: Shiliang Chen conceived the study, designed the experiments, analyzed the data, and wrote the paper. Qiaoling Teng performed the experiments.

Conflicts of Interest: The authors declare no conflict of interest. The founding sponsors had no role in the design of the study; in the collection, analyses, or interpretation of data; in the writing of the manuscript, and in the decision to publish the results.

\section{References}

1. Sorokin, A.B. Phthalocyanine metal complexes in catalysis. Chem. Rev. 2013, 113, 8152-8191. [CrossRef] [PubMed]

2. Sorokin, A.; Seris, J.L.; Meunier, B. Efficient oxidative dechlorination and aromatic ring-cleavage of chlorinated phenols catalyzed by iron sulfophthalocyanine. Science 1995, 268, 1163-1166. [CrossRef] [PubMed]

3. Sorokin, A.B.; Kudrik, E.V. Phthalocyanine metal complexes: Versatile catalysts for selective oxidation and bleaching. Catal. Today 2011, 159, 37-46. [CrossRef]

4. Chen, X.; Lu, W.Y.; Xu, T.F.; Li, N.; Qin, D.D.; Zhu, Z.X.; Wang, G.Q.; Chen, W.X. A bio-inspired strategy to enhance the photocatalytic performance of g-c3n4 under solar irradiation by axial coordination with hemin. Appl. Catal. B-Environ. 2017, 201, 518-526. [CrossRef]

5. Wang, Y.T.; Wang, R.S. A bio-electro-fenton system employing the composite fepc/cnt/ss316 cathode. Materials 2017, 10, 169-184. [CrossRef]

6. Zhu, Z.X.; Chen, Y.; Gu, Y.; Wu, F.; Lu, W.Y.; Xu, T.F.; Chen, W.X. Catalytic degradation of recalcitrant pollutants by fenton-like process using polyacrylonitrile-supported iron (ii) phthalocyanine nanofibers: Intermediates and pathway. Water Res. 2016, 93, 296-305. [CrossRef] [PubMed]

7. Da Silva, T.H.; de Souza, T.F.M.; Ribeiro, A.O.; Calefi, P.S.; Ciuffi, K.J.; Nassar, E.J.; Molina, E.F.; Hamer, P.; de Faria, E.H. New strategies for synthesis and immobilization of methalophtalocyanines onto kaolinite: Preparation, characterization and chemical stability evaluation. Dyes Pigments 2016, 134, 41-50. [CrossRef]

8. Yang, W.X.; Zhang, R.L.; Luo, K.; Zhang, W.P.; Zhao, J.S. Electrocatalytic performances of multi-walled carbon nanotubes chemically modified by metal phthalocyanines in li/socl2 batteries. RSC Adv. 2016, 6, 75632-75639. [CrossRef]

9. De Wael, K.; Adriaens, A. Phthalocyanines and porphyrins linked to gold adatoms and their catalytic property towards hydroxide oxidation. Electrochim. Acta 2008, 53, 2355-2361. [CrossRef]

10. Balkus, K.J.; Eissa, M.; Levado, R. Oxidation of alkanes catalyzed by zeolite-encapsulated perfluorinated ruthenium phthalocyanines. J. Am. Chem. Soc. 1995, 117, 10753-10754. [CrossRef]

11. Han, Z.B.; Han, X.; Zhao, X.M.; Yu, J.T.; Xu, H. Iron phthalocyanine supported on amidoximated pan fiber as effective catalyst for controllable hydrogen peroxide activation in oxidizing organic dyes. J. Hazard. Mater. 2016, 320, 27-35. [CrossRef] [PubMed]

12. Kluson, P.; Drobek, M.; Krejcikova, S.; Krysa, J.; Kalaji, A.; Cajthaml, T.; Rakusan, J. Molecular structure effects in photodegradation of phenol and its chlorinated derivatives with phthalocyanines. Appl. Catal. B-Environ. 2008, 80, 321-326. [CrossRef]

13. Iliev, V.; Alexiev, V.; Bilyarska, L. Effect of metal phthalocyanine complex aggregation on the catalytic and photocatalytic oxidation of sulfur containing compounds. J. Mol. Catal. A-Chem. 1999, 137, 15-22. [CrossRef]

14. Klemm, D.; Kramer, F.; Moritz, S.; Lindström, T.; Ankerfors, M.; Gray, D.; Dorris, A. Nanocelluloses: A new family of nature-based materials. Angew. Chem. Int. Ed. 2011, 50, 5438-5466. [CrossRef] [PubMed]

15. Huang, Y.; Zhu, C.; Yang, J.; Nie, Y.; Chen, C.; Sun, D. Recent advances in bacterial cellulose. Cellulose 2014, 21, 1-30. [CrossRef]

16. Chen, S.; Huang, Y. Bacterial cellulose nanofibers decorated with phthalocyanine: Preparation, characterization and dye removal performance. Mater. Lett. 2015, 142, 235-237. [CrossRef]

17. Eichhorn, S.J.; Dufresne, A.; Aranguren, M.; Marcovich, N.E.; Capadona, J.R.; Rowan, S.J.; Weder, C.; Thielemans, W.; Roman, M.; Renneckar, S.; et al. Review: Current international research into cellulose nanofibres and nanocomposites. J. Mater. Sci. 2010, 45, 1-33. [CrossRef] 
18. Sanchez Marcano, J.G.; Tsotsis, T.T. Catalytic Membranes and Membrane Reactors; Wiley-VCH: Weinheim, Germany, 2002.

19. Dalmon, J.A.; Cruz-Lopez, A.; Farrusseng, D.; Guilhaume, N.; Iojoiu, E.; Jalibert, J.C.; Miachon, S.; Mirodatos, C.; Pantazidis, A.; Rebeilleau-Dassonneville, M.; et al. Oxidation in catalytic membrane reactors. Appl. Catal. A-Gen. 2007, 325, 198-204. [CrossRef]

20. Osegueda, O.; Dafinov, A.; Llorca, J.; Medina, F.; Sueiras, J. Heterogeneous catalytic oxidation of phenol by in situ generated hydrogen peroxide applying novel catalytic membrane reactors. Chem. Eng. J. 2015, 262, 344-355. [CrossRef]

21. Yan, Y.; Jiang, S.S.; Zhang, H.P.; Zhang, X.Y. Preparation of novel fe-zsm-5 zeolite membrane catalysts for catalytic wet peroxide oxidation of phenol in a membrane reactor. Chem. Eng. J. 2015, 259, $243-251$. [CrossRef]

22. Mota, S.; Miachon, S.; Volta, J.-C.; Dalmon, J.-A. Membrane reactor for selective oxidation of butane to maleic anhydride. Catal. Today 2001, 67, 169-176. [CrossRef]

23. Gallucci, F.; Fernandez, E.; Corengia, P.; Annaland, M.V. Recent advances on membranes and membrane reactors for hydrogen production. Chem. Eng. Sci. 2013, 92, 40-66. [CrossRef]

24. Molinari, R.; Lavorato, C.; Argurio, P. Recent progress of photocatalytic membrane reactors in water treatment and in synthesis of organic compounds. A review. Catal. Today 2017, 281, 144-164. [CrossRef]

25. Li, S.; Huang, J.G. Cellulose-rich nanofiber-based functional nanoarchitectures. Adv. Mater. 2016, 28, 1143-1158. [CrossRef] [PubMed]

26. Han, Y.Y.; Wu, X.D.; Zhang, X.N.; Zhou, Z.H.; Lu, C.H. Reductant-free synthesis of silver nanoparticles-doped cellulose microgels for catalyzing and product separation. ACS Sustain. Chem. Eng. 2016, 4, 6322-6331. [CrossRef]

27. Nigiz, F.U.; Hilmioglu, N.D. Simultaneous separation performance of a catalytic membrane reactor for ethyl lactate production by using boric acid coated carboxymethyl cellulose membrane. React. Kinet. Mech. Catal. 2016, 118, 557-575. [CrossRef]

28. Unlu, D.; Hilmioglu, N.D. Synthesis of ethyl levulinate as a fuel bioadditive by a novel catalytically active pervaporation membrane. Energy Fuels 2016, 30, 2997-3003. [CrossRef]

29. Ramaraju, B.; Imae, T.; Destaye, A.G. Ag nanoparticle-immobilized cellulose nanofibril films for environmental conservation. Appl. Catal. A-Gen. 2015, 492, 184-189. [CrossRef]

30. Chen, P.C.; Huang, X.J.; Xu, Z.K. Utilization of a biphasic oil/aqueous cellulose nanofiber membrane bioreactor with immobilized lipase for continuous hydrolysis of olive oil. Cellulose 2014, 21, 407-416. [CrossRef]

31. Yang, J.; Sun, D.; Li, J.; Yang, X.; Yu, J.; Hao, Q.; Liu, W.; Liu, J.; Zou, Z.; Gu, J. In situ deposition of platinum nanoparticles on bacterial cellulose membranes and evaluation of pem fuel cell performance. Electrochim. Acta 2009, 54, 6300-6305. [CrossRef]

32. Chen, S.; Huang, X.; Xu, Z. Functionalization of cellulose nanofiber mats with phthalocyanine for decoloration of reactive dye wastewater. Cellulose 2011, 18, 1295-1303. [CrossRef]

33. Achar, B.; Fohlen, G.; Parker, J.; Keshavayya, J. Synthesis and structural studies of metal (ii) 4, 9, 16, 23-phthalocyanine tetraamines. Polyhedron 1987, 6, 1463-1467. [CrossRef]

34. Liu, H.Q.; Hsieh, Y.L. Ultrafine fibrous cellulose membranes from electrospinning of cellulose acetate. J. Polym. Sci. Part B-Polym. Phys. 2002, 40, 2119-2129. [CrossRef]

35. Huang, X.J.; Chen, P.C.; Huang, F.; Ou, Y.; Chen, M.R.; Xu, Z.K. Immobilization of candida rugosa lipase on electrospun cellulose nanofiber membrane. J. Mol. Catal. B-Enzym. 2011, 70, 95-100. [CrossRef]

36. Ma, Z.; Ramakrishna, S. Electrospun regenerated cellulose nanofiber affinity membrane functionalized with protein a/g for igg purification. J. Membr. Sci. 2008, 319, 23-28. [CrossRef]

37. Beamson, G. High resolution xps of organic polymers. Anal. Chim. Acta 1993, 276, 469-470.

38. Nilson, K.; Palmgren, P.; Ahlund, J.; Schiessling, J.; Gothelid, E.; Martensson, N.; Puglia, C.; Gothelid, M. Stm and xps characterization of zinc phthalocyanine on insb(001). Surf. Sci. 2008, 602, 452-459. [CrossRef]

39. Lu, W.Y.; Li, N.; Chen, W.X.; Yao, Y.Y. The role of multiwalled carbon nanotubes in enhancing the catalytic activity of cobalt tetraaminophthalocyanine for oxidation of conjugated dyes. Carbon 2009, 47, 3337-3345. [CrossRef] 
40. Zemljic, L.F.; Strnad, S.; Sauperl, O.; Stana-Kleinschek, K. Characterization of amino groups for cotton fibers coated with chitosan. Text. Res. J. 2009, 79, 219-226. [CrossRef]

41. Chen, W.X.; Lu, W.Y.; Yao, Y.Y.; Xu, M.H. Highly efficient decomposition of organic dyes by aqueous-fiber phase transfer and in situ catalytic oxidation, using fiber-supported cobalt phthalocyanine. Environ. Sci. Technol. 2007, 41, 6240-6245. [CrossRef] [PubMed]

42. Chen, S.; Huang, X.; Xu, Z. Decoration of phthalocyanine on multiwalled carbon nanotubes/cellulose nanofibers nanocomposite for decoloration of dye wastewater. Compos. Sci. Technol. 2014, 101, 11-16. [CrossRef]

43. Yamazaki, I.; Piette, L.H. Epr spin-trapping study on the oxidizing species formed in the reaction of the ferrous ion with hydrogen-peroxide. J. Am. Chem. Soc. 1991, 113, 7588-7593. [CrossRef]

2017 by the authors. Licensee MDPI, Basel, Switzerland. This article is an open access article distributed under the terms and conditions of the Creative Commons Attribution (CC BY) license (http:/ / creativecommons.org/licenses/by/4.0/). 